\title{
Building information model implementation for existing buildings for facilities management: a framework and two case studies
}

\author{
G. Carbonari, S. Stravoravdis \& C. Gausden \\ Department of Built Environment, University of Greenwich, UK
}

\begin{abstract}
This paper presents the process of implementation of a building information model for managing an existing building, identifying a development framework and documenting the difficulties that occurred during the implementation of the initial stages. The use of building information modelling (BIM) for the design and construction phase of a building has been thoroughly looked into by researchers and practitioners and there is evidence to support that it is beneficial for reducing cost, time and improving communication. A single shared building information model results in a greater accuracy, clarity and consistency of the information available during the life cycle compared to traditional 2D/3D drawings. Yet the potential use of BIM for the operational and management phase (facilities management), besides maintenance schedules and equipment information and location, is still not clearly identified. The UK Government, institutional clients and major private owners are now demanding BIM for new construction and major refurbishment, but given that $70-75 \%$ of the UK building stock that will exist and be in use in 2050 has already been built, a significant part of the existing facilities will not have a building information model till the next major refurbishment. This creates a major gap in the built environment, when it comes to having BIM for existing buildings.

This paper presents the initial findings of two case studies, where building information models were developed for two existing buildings using a new framework and concludes that minimal BIM skills are sufficient to construct a base building model that can be implemented over time by facilities managers.

Keywords: BIM, existing buildings, facilities management, information management.
\end{abstract}




\section{Introduction}

The number of companies using BIM for the design and construction of new buildings is constantly growing $[1,2]$ : this technology is developing fast and it is used to accommodate the growing complexity of new construction projects [3]. BIM is an information management process [4] that can be used at all stages of a building's life-cycle: from understanding the project needs of the owner, to evaluate designs, manage the construction process and operate the building until decommissioning [5]. A building information model can reduce costs, provide support to a more efficient project delivery process [6] and enhance collaboration and knowledge sharing [7, 8]. The many benefits of BIM during design, planning and construction $[9,10]$ have been studied both by practitioners and academics but for building operations and facilities managers, BIM is still a relatively new topic: its potential is still not fully understood and there is little interest regarding what happens once the building model is completed and handed over, and how BIM will be used to manage the facility beside the possible use for enhanced building maintenance [11]. BIM awareness and adoption growth has been significantly influenced by the UK Government strategy for the construction industry [12]. BIM Level 2, mandate for all Government projects by 2016, is based on a collaborative digital environment and focuses mainly on design and construction, while BIM Level 3, now Digital Built Britain, "will extend BIM into the operation of assets over their lifetimes" [13]. The full collaboration between all disciplines involved in a construction project aimed for BIM Level 3 will get facilities managers more involved with the modelling technology. Only recently researchers have started looking at the possible integration of BIM and FM but the main focus is on new constructions rather than existing buildings [9]. However, given the number of existing buildings in the UK estimated to be in use by $2050(70-75 \%)$ [14] there is the need to address the problem of creating building information models for the existing estates. Facility managers are constantly challenged to improve and standardize all available information to address day-to-day operations and lifecycle management [6]. Nowadays, buildings information is often incomplete or obsolete $[15,16]$ hence during operation "an inordinate amount of time is spent locating and verifying specific facility and project information" [17]. BIM provides integration of data systems during the building's life cycle [6], therefore there is an opportunity for facilities managers to improve the current practice and use BIM as a decision making tool. There are several potential benefits of using BIM during operations and maintenance that confirm the importance of extending BIM to facilities management practice and create models for existing buildings: the availability of as-built information [10], the development of maintenance schedule, the opportunity to track and maintain lifecycle information about the building structure [18] together with the opportunity to improve performances [6].

The purpose of this paper is to present the initial stages of the development of a new framework aimed at creating building information models for existing buildings. Section 2 discusses how the information model should be developed according to the PAS 1192. Section 3 focuses on the technologies currently available to create models for existing buildings. Section 4 presents the research 
methodology and the two buildings used as case studies for the research. Section 5 outlines the RetroBIM framework and the future developments of the study and Section 6 concludes with the research findings.

\section{PAS 1192}

Over the building life cycle the amount of graphics and data required varies from stage to stage (Figure 1): the volume of graphical information, fundamental during the design stage, decreases once the design is complete, while attribute data become more important during the construction and operation phases [6].
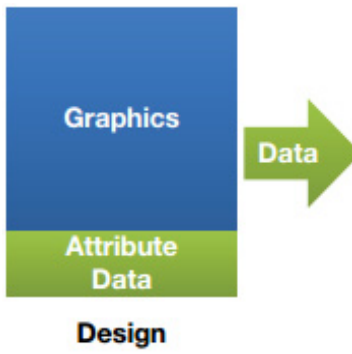

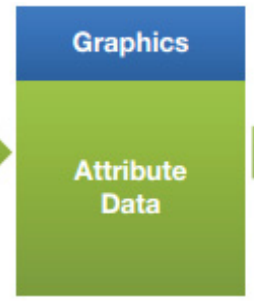

Construct

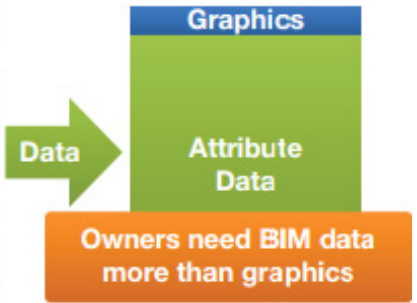

Operate

Figure 1: Graphics and data over building life cycle [6].

By combining both "physical and functional characteristics of a facility" [19] BIM can easily accommodate the different users' needs during the building's life cycle. In order to create a data-rich model, bespoke to each organisation's needs, the British Standards Institution published, in 2013, the Publicly Available Specification (PAS) 1192 Part 2 "Specification for information for the capital/delivery phase of construction projects using building information modelling" [20]. PAS 1192-2 determines a set of standards needed to meet the BIM Level 2 requirements for new constructions or refurbishments and ensure a collaborative digital environment. Through the various stages of the Information Delivery Cycle (IDC), the PAS 1192-2 provides a framework for the creation and development of an information model that results, after the project handover, in the delivery of the as-constructed asset information model (AIM). Information within the model grows as the project moves from stage 1 (brief) to stage 6 (handover and closeout), and is based on the Employer's Information Requirements (EIR) identified at the beginning of the process. During the operational phase, analysed in the PAS 1192 Part 3 [21] the AIM will evolve accordingly to the events (e.g. major and minor works, breakdowns, transfer ownership) that occur while the building is in use. The PAS 1192-3 "Specification for information management for the operational phase of construction projects using building information modelling" is meant to be used during the building operation for maintenance and strategic management [22]; however, the standards do not provide a framework for existing buildings that are not about to undertake major refurbishment, therefore leaving a gap when it comes to BIM for existing estates. 


\section{$3 \quad$ BIM for existing buildings}

Although it would be ideal to have as-constructed asset information model available for every building, most of the existing estates have been built before the "BIM era" and albeit the number of projects using BIM nowadays is growing, it is still not being applied to all new constructions. Technology allows to create asbuilt models that can be used during buildings operation phase but, according to Kassem et al. [17], a lack of clients' demand to implement models for FM together with "a shortage of BIM skills and understanding by FM professional... is creating a vicious circle inhibiting BIM adoption in FM applications".

The most commonly used process to create an as-built 3D model is Scan-toBIM through 3D laser scanning [24]. 3D laser scanning is an imaging technology in use since 1990: with millimetre accuracy the 3D laser scanning allows the creation of detailed data about a building [25]. The technology is faster and more accurate than traditional surveys methodologies [26], offers a large range of possible applications and it is currently the most accurate approach for creating models for existing buildings [27]. However, there are some potential difficulties in the Scan-to-BIM process: indoor scans are not as accurate and fully automated as for external shapes [28,29], complex design can make the process more difficult and the huge amount of data created during the scanning often lead to slowdown or failure of the process [30]. Moreover, the equipment required for the scanning has high costs and requires data processing and modelling [31].

Due to the complexity of the process (data capturing, processing and model creation), the effort [31] and time needed, the advanced skills required and overall costs [27], there is a lack of interest in modelling existing buildings. The purpose of the research is to develop a new framework aimed at creating building information models for existing buildings, filling the gap identified in Section 2.

\section{Methodology}

The purpose of the research is to identify a new methodology envisioned to enable the creation of information models for every kind of building currently in use.

The approach used in this study involved a literature review, aimed at understanding the current gap, the development of a framework aimed at filling the current gap, based on the literature, in particular PAS 1992, and finally a practical test of the initial phase of the framework on two case studies buildings. The case studies selected are existing non-domestic buildings at different stages of their lifecycle that do not have a building information model. The buildings were selected based on the opportunity to access the information required for this stage and the following stages of the research and whether there was a willingness by facilities managers to work alongside them, in order to understand how their facilities are managed. Although the results of the research cannot be generalized because of the small sample size, the various sources of evidence can help better understand the time and effort investment required by a facility manager to create an information model for existing buildings without having to resort to 3D laser scanning. The models for the two buildings were created using Revit. The 
researcher attended a two-day workshop on the software and made use of online tutorials for additional help during the creation of the models.

\subsection{Case studies}

\subsubsection{Case I: Belmont House}

Belmont House (Figure 2) is currently leased to the Redcar \& Cleveland Borough Council and is managed by BAM FM since 2002. The building consists of three floors over $4100 \mathrm{~m}^{2}$ : each floor combines open spaces, private offices and meeting rooms, with a total of 103 rooms. The ground floor is partially used to provide public services while the first and second floors are for staff use only.

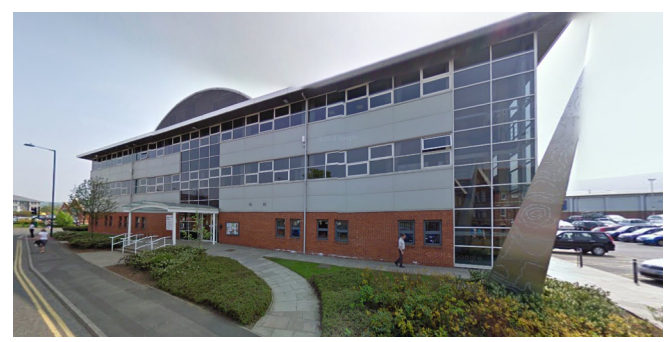

Figure 2: Belmont House [32].

\subsubsection{Case II: Medway University Technical College}

Medway University Technical College (Figure 3) is a new secondary school located in the Chatham Waters regeneration site in north Gillingham, Kent [33]. The UTC consists of four floors over $6100 \mathrm{~m}^{2}$ that accommodates learning facilities, workshop rooms and staff offices, in addition to a court sport hall, a refectory and a forum.

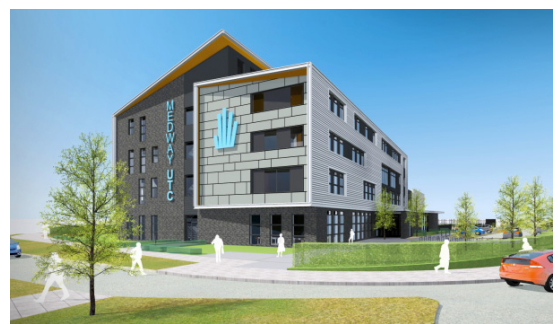

Figure 3: $\quad$ Medway UTC [33].

\section{RetroBIM framework}

Information is vital for facilities management [34] and an easy access to the required information is essential to operate a building in an effective way [6]. 
Nevertheless most of the documents handed over to facilities managers by contractors are still paper based [23] and thousands of man-hours are spent recreating [35] incomplete and inaccurate [36] information. Technology has helped FM to automate the traditional processes $[37,38]$ but it is still perceived as a utility tool rather than an enabler for strategic value [39]. Most of the FM functions are done manually [40], but using BIM would increase efficiency and accuracy [15] and the building model would be used as a single source for all the project information [41]. Nevertheless, there is an important issue that needs to be addressed regarding the creation of a model for existing buildings: every project is different and the requirements within each model vary [31] based on the building, its use, the management strategies and the users and all these aspects should be considered when a BIM for FM model is created. The differences highlighted preclude the identification of a unique set of information that could be used to create models for every building during the operational phase: every building will in fact require a different breadth and depth of information stored and recorded during the life cycle [42]. Accordingly with the literature BIM in FM is still at a very early phase of implementation and acquiring the data needed for managing the buildings is a major obstacle [43]. The motivation for this research is to create a new approach to the generation of information models of existing buildings aimed at simplifying the development process by giving the opportunity to the facilities managers to create models tailored on the building, the management strategies and the users. The framework is called RetroBIM (Figure 4) and it is an iterative process based on the increasing level of model details (information).

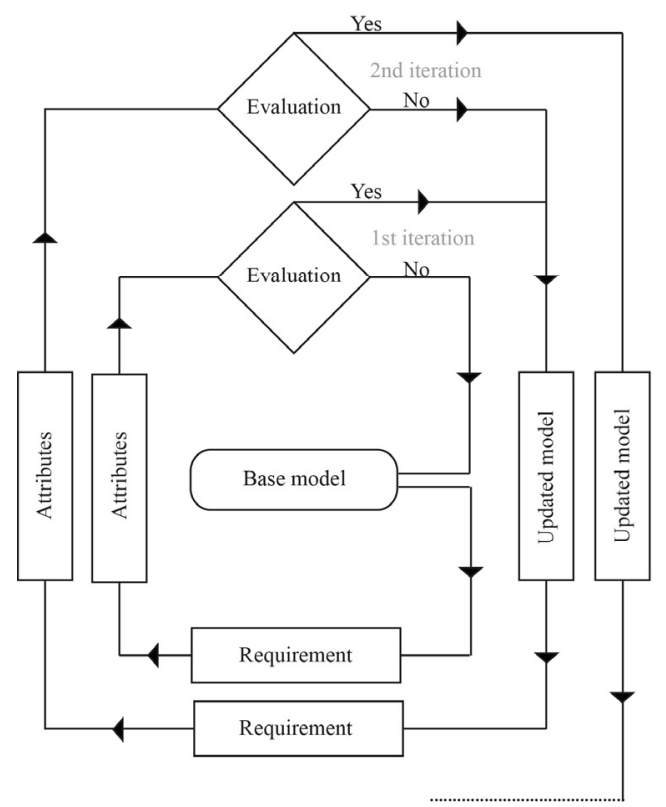

Figure 4: RetroBIM framework. 
The framework starts with the base model: a 3D graphical representation of the building which includes internal and external walls, windows and doors. Once the base model is complete the facilities manager identifies what is required to operate and maintain the building and to answer operational decisions. The requirements can be identified at business, functional and operational level to fulfil both shortterm and long-term strategy needs and day-to-day operations. Each requirement is then translated into attributes that may contain information about dimensions, identification, performance, installation/application, sustainability/usage, management and maintenance or specifications [44] of the model's elements. At the end of each iteration the facilities manager evaluates whether the requirement and connected attributes are needed in the model for future purposes or not: if yes, the model will be updated according to the new set of information. At each iteration additional requirements and attributes are evaluated and the model develops over time based on each organisation's and building's needs: the model will grow over time and include the breadth and depth of information appropriate for each project.

\subsection{Creating the base models}

\subsubsection{Belmont House base model}

In order to create the model, the building was surveyed by one person using a laser distance measurer. The survey took 8 hours to be completed and to ensure accuracy every measurement was taken three times and recorded: the average value of each measurement was then used to create the final model.

The building has a linear design and the process of developing the model took approximately 7 hours and 30 minutes, with an average of $547 \mathrm{~m}^{2}$ every hour. The main difficulty encountered was the creation of the glazing and it was overcome by creating intermediate levels between the first and second floor and between second floor and the roof.

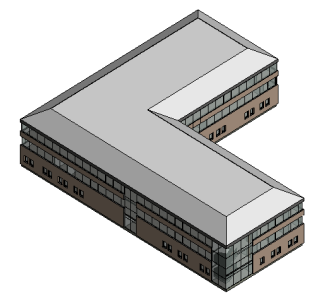

Figure 5: Belmont House 3D view. Figure 6: Belmont House front view.

\subsubsection{Medway UTC base model}

In order to create the model, the researcher used the floor maps, elevations and sections provided by the lead building contractor. Certain elements in the design of the UTC affected the development of the model: the multi levels roofs, the 
internal void for the forum and the court sports hall. The model was completed in approximately 13 hours, with an average of $469 \mathrm{~m}^{2}$ completed every hour.
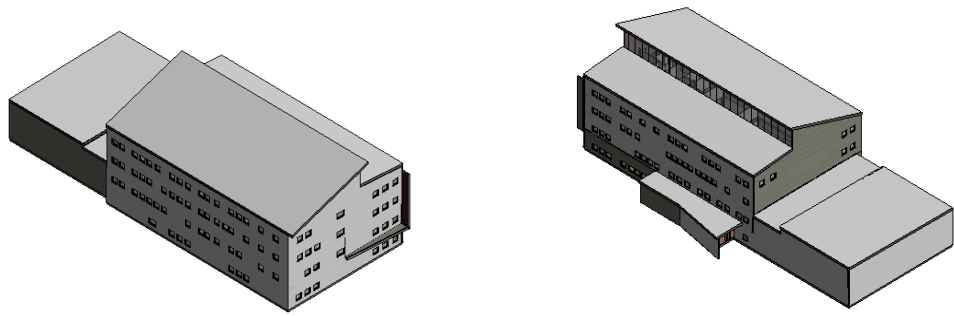

Figure 7: UTC Medway 3D views.

\section{Conclusion}

The benefits derived from the use of BIM for the management of buildings should be extended to existing buildings that currently have no models. Despite the existence of technologies that allow creation of 3D models of the existing estates, such as Scan-to-BIM, these are rarely used due to several limitations.

The RetroBIM framework proposed in this paper describes a new methodology to develop bespoke information models for existing buildings based on the facilities management strategy and the buildings' requirements. The case study presented, although with limitations, proves that the base model, the starting point of the framework, can be created without using costly and time consuming technologies. The test proves that models for facilities management are different from the one developed during design and construction. The graphic part should be minimal, as confirmed by the literature, and the main focus should be on the identification of the key data set to create whole-life models. Minimal BIM skills are sufficient to create the base models and even without full architecture details, the model can be used to enhance and improve operation tasks such as space management. Hence, the base model can be created by facilities managers and used to replace 2D floor maps currently in use for day-to-day operations. By adding information through the requirement/attributes/evaluation loop the model will grow over time, becoming a detailed decision making tool for facilities managers to fulfil both short-term and long-term strategy needs and day-to-day operations. Compared with the technologies available for modelling existing buildings, the framework proposed in this paper does not require the involvement of external experts, has no additional capital cost apart from the time commitment of a facilities manager to create the model and the implementation time is significantly reduced. Where BIM modelling skills do not exist, there is an issue. Hence the framework can be applied to every type of building, without limitations, and enables every facilities manager to fully benefit from using building information models during the operation phase. Facilities managers are often very busy with little time available for additional activities such as creating BIM models of the assets they manage and there is a potential lack of BIM modelling skills in 
the field. Both can be limiting factors in adopting RetroBIM, but with a one-off training investment, as well as the employment of graduate facilities managers, many of whom already possess BIM modelling skills, these issues could be addressed.

The next step of the research will involve the identification of requirements and attributes necessary to manage a building. This will be based on the different tasks usually undertaken by facilities managers, identified through literature and an online survey. Once the framework is complete, it will be applied to the case studies buildings for a set number of iterations. To improve the validity of the study two more case studies will be added to test the framework on a more complex building ('Stockwell Street', library and academic building at the University of Greenwich, opened in September 2014) and on a Grade II listed building that will undertake major refurbishment over the next two years ('Dreadnought Library' library and computer centre at the University of Greenwich, built between 1764-1786).

\section{References}

[1] D. Bryde, M. Broquetas and J. Volm, “The project benefits of Building Information Modelling (BIM)," International Journal of Project Management, vol. 31(2013), pp. 971-980, 2013.

[2] J. Underwood and U. Isikdag, "Emerging technologies for BIM 2.0," Construction Innovation, vol. 11, no. 3, pp. 252-258, 2011.

[3] A. Grilo and R. Jardim-Goncalves, "Value proposition on interoperability of BIM and collaborative working environments," Automation in Construction, vol. 19, no. 5, pp. 522-530, 2010.

[4] IFMA, BIM for facility managers, P. Teicholz, Ed., Hoboken, New Jersey: John Wiley \& Sons, 2013.

[5] SmartMarket Report, "Building Information Modeling (BIM)," McGrawHill Construction, Bedford, 2008.

[6] SmartMarket Report, "The Business Value of BIM for Construction in Major Global Markets: How Contractors Around the World Are Driving Innovation With Building Information Modeling," McGraw Hill Construction, Bedford, 2014.

[7] Digital Built Britain, "Digital Built Britain: our vision," (Online). Available: http://digital-built-britain.com/vision. (Accessed 04 May 2015).

[8] M. Gray, J. Gray, M. Teo, S. Chi and F. Cheung, "Building Information Modeling, An International Survey," (Online). Available: http://www.irbnet.de/daten/iconda/CIB_DC27530.pdf.

[9] J. Ravetz, "State of the Stock What do we know about existing buildings and their future prospects?" Energy Policy, vol. 36, pp. 4462-4470.

[10] A. O'Connor, J. Dettbarn and L. Gilday, "Cost analysis of inadequate interoperability in the US capital facilities industry," 2004. (Online). Available: http:/www.nist.gov/manuscript-publication-search.cfm ?pub_id=101287. (Accessed 04 May 2015). 
[11] T. Eastman, L. Sacks, R. Sacks and K. Liston, BIM Handbook - a guide to building information modeling for owners, managers, designers, engineers and contractors, Hoboken: John Wiley \& Sons, 2011.

[12] G. Carbonari and K. Jones, "Sustainable Facilities Management through Building Information Modelling," in 13th EuroFM Research Symposium, Berlin, 2014.

[13] BuildingSMARTalliance, "United States National Building Information Modelling Standard Version 1 - Part 1: Overview, Principles, and Methodologies," National Institute of Building Sciences, 2007.

[14] The British Standards Institution, "PAS 1192-2:2013 Specification for information management for the capital/delivery phase of construction projects using building information modelling," The British Standards Institution, 2013.

[15] The British Standards Institution, "PAS 1192-3:2014 Specification for information management for the operational phase of assets using building information modelling," The British Standards Institution, 2014.

[16] S. Mordue, "PAS 1192-3," December 2013. (Online). Available: http://www.thenbs.com/topics/bim/articles/pas1192-3.asp. (Accessed 05 May 2015).

[17] M. Kassem, G. Kelly, N. Dawood, M. Serginson and S. Lockley, "BIM in facilities management applications: a case study of a large university complex," Built Environment Project and Seet management, vol. 5, no. 3, 2015.

[18] H. Hajian and B. Becerik-Gerber, "Scan to BIM: factors affecting operational and computational errors and productivity loss," in 27th International Symposium on Automation and Robotics in Construction, 2010.

[19] F. Bosché, A. Guillemet, Y. Turkan, C. Haas and R. Haas, "Tracking the Built Status of MEP Works: Assessing the Value of a Scan-vs.BIM System," Journal Computing in Civil Engineering, vol. 28, 2014.

[20] B. Lijing and Z. Zhengpeng, "Application of point clouds from terrestrial 3D laser scanner for deformation measurements," in International Society for Photogrammetry and Remote Sensing, 2008.

[21] L. Gimenez, J.-L. Hippolyte, S. Robert, F. Suard and K. Zreik, "Review: reconstruction of 3D building information models from 2D scanned plans," Journal of Building Engineering, vol. 2, pp. 24-35, 2015.

[22] J. Jung, S. Hong, S. Jeong, S. Kim, H. Cho, S. Hong and J. Heo, "Productive modeling for development of as-built BIM of existing indoor structures," Automation in Construction, vol. 42, pp. 68-77, 2014.

[23] R. Volk, J. Stengel and F. Schultmann, "Building Information Modeling (BIM) for existing buildings - Literature review and future needs," Automation in Construction, vol. 38, pp. 109-127, 2014.

[24] Google Maps. (Online). Available: https://www.google.co.uk/maps/ @ $54.532832,-1.055026,3 \mathrm{a}, 90 \mathrm{y}, 128.74 \mathrm{~h}, 92.21 \mathrm{t} / \mathrm{data}=! 3 \mathrm{~m} 4 ! 1 \mathrm{e} 1 ! 3 \mathrm{~m} 2$ ! 1sOSRKcjgXkj5O55q1cLqmUQ!2e0. (Accessed 01 May 2015). 
[25] UTC Medway. (Online). Available: http://medwayutc.co.uk/medway/. (Accessed 01 May 2015).

[26] D. Jordani, "BIM and FM: The Portal to Lifecycle Facility Management," Journal of Building Information Modeling, vol. Spring 2011, pp. 13-16, 2010.

[27] R. Keady, "Financial Impact and analysis of equipment inventories," Facilities Engineering Journal, vol. 27, no. 5, pp. 13-17, 2009.

[28] J. E. A. Lucas, "An object-oriented model to support healthcare facility information management," Automation in Construction, vol. 31, pp. 281291, 2013.

[29] G. Antoniou and F. van Harmelen, "A Semantic Web Primer,” MIT Press, 2008.

[30] A. Motamed, A. Hammad and Y. Asen, "Knowledge-assisted BIM-based visual analytics for failure root cause detection in facilities management," Automation in Construction, vol. 43, pp. 73-83, 2014.

[31] B. Becerik-Gerber, F. Jazizadeh, N. Li and G. Calis, "Application areas and data requirements for BIM-enabled facilities management," Journal of Construction Engineering and Management, vol. 138, no. 3, pp. 431-442, 2012.

[32] General Services Administration, "GSA Building Information Modeling Guide Series: 08 - GSA BIM Guide for Facility Management. Version 1 December 2011," US General Services Administration, Public Buildings Service, Office of Design and Construction, 2011.

[33] G. Carbonari, S. Ashworth and S. Stravoravdis, "How Facility Management can use Building Information Modelling (BIM) to improve the decision making process," Journal of Facility Management, vol. 10, no. 2015, 2015.

[34] P. Ebbesen, "Information Technology in Facilities Management - A Literature Review," in 14th EuroFM Research Symposium, Glasgow, 2015.

[35] R. Weygant, BIM Content development, John Wiley \& Sons: Hoboken, 2011.

[36] NBS, “National BIM Report 2014,” RIBA Enterprises Ltd, 2014.

[37] A. Salman, "Building Information Modelling (BIM): Trends, Benefits, Risks and Challenges for the AEC Industry," Leadership \& Management in Engineering, vol. 11, no. 3, pp. 241-252, 2011.

[38] K. Jones and S. Collis, "Computerised maintenance management systems," Property Management, vol. 14, no. 4, pp. 33-37, 1996.

[39] R. Kivits and C. Furneaun, "BIM: Enabling Sustainability and Asset Management through Knowledge Management," The Scientific World Journal, vol. 2013.

[40] D. Remenyi, T. White and M. Sherwood-Smith, "Information systems management: the need for a postmodern approach," vol. 17, no. 6, pp. 421436, 1997.

[41] E. Valero, A. Adan and C. Cerrada, "Automatic Construction of 3D BasicSemantic Models of Inhabited Interiors Using Laser Scanners and RFID Sensors," Sensors, vol. 12, no. 5, pp. 5705-5724, 2015. 
[42] X. Xiong, A. Adan, B. Akinci and D. Huber, "Automatic creation of semantically rich 3D building models from laser scanner data," Automation in Construction, vol. 31, pp. 325-337, 2013.

[43] I. Gursel, S. Sariyildiz, O. Akin and R. Stouffs, "Modeling and visualization of lifecycle building performance assessment," Advanced Engineering Informatics, vol. 23, no. 4, pp. 396-417, 2009.

[44] S. Ho, H. Tserng and S. Jan, "Enhancing Knowledge Sharing Management Using BIM Technology in Construction," The Scientific World Journal, vol. 2013, p. 10, 2013. 